\title{
VERBALIDAD, POLÍTICA Y POESÍA EN EL TEATRO DE GUILLERMO CALDERÓN
}

\author{
Juan Andrés Piña
}

\begin{abstract}
RESUMEN: El presente ensayo recorre la obra de uno de los más importantes autores del teatro chileno de los últimos años: Guillermo Calderón, quien en obras como Neva, Diciembre, Clase, Villa y Discurso recupera el valor esencial del dramaturgo como protagonista del acontecimiento escénico. Sus creaciones, apoyadas en una robusta verbalidad que adquiere tonos poéticos, elegíacos y realistas, hablan de temas políticos y sociales del Chile actual, planteados como conflictos aún no resueltos por la comunidad nacional.

PALABRAS CLAVE: verbalidad, política, drama nacional, dramaturgo, escena.
\end{abstract}

\section{VERBALITY, POLITICS AND POETRY IN THE THEATRE OF GUILLERMO CALDERÓN}

ABSTRACT: This article covers the work of one of the most important authors of the Chilean theatre in recent years: Guillermo Calderón, who in works such as Neva, Diciembre, Clase, Villa $y$ Discurso

Juan Andrés PiÑa (Santiago, 1953). Periodista y magíster en literatura hispanoamericana, ambos títulos por la Pontificia Universidad Católica de Chile. Ha ejercido el periodismo cultural por cuarenta años en diversos medios de comunicación, nacionales y extranjeros. Ha sido crítico teatral de las revistas Mensaje, Hoy y Apsi, del suplemento Artes y Letras del diario El Mercurio y de La Tercera. Entre su libros se encuentran Conversaciones con la poesía chilena (1990); 20 años de teatro chileno. 1976-1996 (1998); El problema Shakespeare y otros temas del teatro contemporáneo (2002); Historia del teatro en Chile. 1890-1940 (2009); Contingencia, poesía y experimentación: teatro chileno. 1976-2002 (2010); Historia del teatro en Chile.1941-1990 (2014).Email: juanandrespina@gmail.com 
retrieves the essential value of the playwright as the protagonist of events on the stage. His creations, backed by a robust verbality that acquires poetic, elegac and realistic tones, speak of political and social issues of present-day Chile, posed as still unresolved disputes by the national community.

KEYWORDS: verbality, policy, national drama, play-wright, scene.

$E^{\prime}$ 1 surgimiento del escritor y director chileno Guillermo Calderón ${ }^{1}$ en la escena chilena en 2006 con Neva (estrenada por su compañía Teatro en el Blanco) ayudó a confirmar algo que desde hacía algún tiempo se venía observando en nuestra cultura contemporánea: la revitalización de la figura del dramaturgo como protagonista indiscutible del acontecimiento teatral. El cuestionamiento de su papel esencial en los montajes había sido progresivo desde mediados de los años sesenta, tanto en Estados Unidos como en Latinoamérica, donde los montajes generados por los actores de una compañía, con la decidida colaboración del director, trabajaron para sepultar a quien consideraban un sujeto esencialmente literario, libresco, lejano a la esencia propiamente escénica: el autor dramático.

Ya en esos años se formularon apocalípticos pronósticos respecto de la desaparición, incluso, de la escritura teatral. El dramaturgo, que antes había sido la sustancia ineludible de un montaje - reafirmado por la influencia del realismo psicológico de los cincuenta-, con el tiempo tuvo que dejar paso a las experiencias de los "teatro taller" y después a la "creación colectiva", las que lo requirieron apenas como un "aportador de textos", "organizador de la improvisación de los actores" o "coautor en la escritura de la obra", y ya no como quien entregaba una personal visión de mundo que debía plasmarse sobre el escenario gracias al trabajo de una compañía. Estos calificativos resultaron humillan-

${ }^{1}$ Guillermo Calderón nació en Santiago en 1971. Estudió actuación en la Escuela de Teatro de la Universidad de Chile. Realizó estudios de postgrado en el Actor's Studio, en Nueva York; en la Escuela de Teatro Físico Dell'Arte, en California, y un máster en teoría del cine, en la City University de Nueva York. Ganó el premio del Círculo de Críticos en los años 2006 y 2008, dos premios Altazor y el premio José Nuez Martín en 2008. Como director, ha llevado a escena textos de otros dramaturgos. 
tes para algunos autores que se negaban a participar en una miscelánea creativa lejana a su formación y a sus intereses.

Sin embargo, quedaba más, ya que desde finales de los años setenta y por bastante tiempo su crisis se acrecentó: en esa época se consolidaron los espectáculos donde los aspectos visuales, plásticos, lumínicos y sonoros opacaron, por no decir hundieron, cualquier verbalidad posible. Entonces fue la palabra misma - la lengua como mecanismo de comunicación y de invención - la que quedó damnificada, al punto de que era normal afirmar que aquella palabra constituía un elemento más dentro del espectáculo, otro código entre los varios que poblaban el escenario, la que en ocasiones resultaba incómoda para muchos componentes de las nuevas generaciones de teatristas.

Para graficar esta repulsa por el lenguaje, usaban el calificativo de "teatro de texto" cuando se referían a determinados espectáculos, sentencia que acompañaban con un gesto despectivo. Incluso un montaje chileno como Malasangre (1991) se basaba sólo en música, gestualidad y movimientos, aunque nadie podía negar que allí había una obra de teatro. Los impulsores de estas poéticas contemporáneas se proclamaban intérpretes — cómo no- del teórico francés Antonin Artaud (18961948), a quien decían representar en toda su esencia. Con el paso de los años, se demostró que muchas veces aquellas lecturas fueron erradas, arbitrarias o deficientes.

Obviamente que esta vorágine incluyó también al teatro psicológico-realista, sobre todo a las piezas de los autores norteamericanos clave en el desarrollo del arte de posguerra (Eugene O'Neill, Tennessee Williams, Arthur Miller). Se les censuró todo: que delinearan personajes, que narraran anécdotas, que fueran demasiado veraces. Sin embargo, contra todos los pronósticos, aquellas vapuleadas obras han vuelto a ser montadas en la última década en las principales capitales del mundo, y con éxito singular. Su renovada recepción se debió a que los nuevos espectadores, desprejuiciados y atentos, vieron que allí había profundidad en el tratamiento de las relaciones humanas, en sus pulsiones y enigmas; entendieron que sus historias estaban perfectamente organizadas y apreciaron sus potentes metáforas respecto de la condición de las personas, así como el retrato de los dolores y los anhelos de una sociedad que se interroga sobre problemas permanentes. Es decir, había allí una dramaturgia de asombrosa vigencia. 


\section{LA RESTAURACIÓN DE LA VERBALIDAD}

La dramaturgia de Calderón es heredera de ciertos autores europeos que, en medio de aquellas crisis, trabajaron por la recuperación de la fuerza de la oralidad, la potenciaron y redescubrieron desde su esencia misma: la palabra como factor resolutivo y plasmador de un mundo. No se trata ya de aquella palabra sustancialmente utilitaria, al servicio de unos diálogos más o menos informativos, o de una palabra necesariamente puesta en la boca de personajes psicológicamente definidos e identificables, sino de un verbo cercano a la poesía y al mito, al tono narrativo; una especie de manantial expresivo, la recreación de una lengua a veces de registro lírico, inventora de una atmósfera y de una historia.

En esta restauración de la verbalidad, el dramaturgo francés Bernard Marié Koltès (1948-1989) y el alemán Heiner Müller (1929-1995), entre otros, influyeron significativamente en las nuevas generaciones de autores de todo el mundo. Sus obras están estructuradas sobre la base de extensos y poéticos diálogos que progresivamente se transforman en un torrente de extraña y hermosa sonoridad. En el caso de Koltès, los textos se alejan de los conceptos clásicos del uso de la palabra: no hay una entrega convencional de la información ni un relato que haga avanzar la historia, sino que es un incesante oleaje de oralidad que busca expresar un mundo íntimo y metafórico, encerrado en el cuerpo del personaje y que angustiosamente pugna por salir.

De esta manera, las tajantes profecías que anunciaban la desaparición del verbo en escena - así como la extinción definitiva del relato e, incluso, de los personajes más o menos identificables-, formuladas por gente del teatro en momentos de éxtasis, no se cumplieron. Es más, desvanecida la euforia del teatro visual y cinético, y cuando quedó patente su ausencia de contenidos así como la futilidad de sus temas, se buscó nuevamente a dramaturgos - de la antigüedad y del presente- que pudieran entregar contenidos verdaderos, ideas, conceptos, propuestas allí donde sólo quedaba una carcasa vacía y sin trascendencia. Así las cosas, incontables grupos de todo el mundo retornaron a aquello que antes habían despreciado: el famoso "teatro textual". Desde entonces se asiste, igualmente, al reestreno de célebres piezas de todos los tiempos.

En este contexto, no es extraño que Calderón haya sido saludado como un dramaturgo de la renovación, por trabajar sobre la base de una poderosa verbalidad, para estructurar con ella un universo reflexivo y atento a los acontecimientos del mundo y de Chile, y capaz de formu- 
lar interrogantes a las verdades recibidas. Todas sus obras se sostienen en largos parlamentos que los personajes se dicen a sí mismos o a los demás, creando con ello una singular poética que va desde la apagada sordina interior hasta alcanzar niveles épicos.

La importancia de la palabra es tan clave en su producción que si se observa en detalle se verá que los elementos físicos de la escenografía, incluida la iluminación, son aquellos mínimamente necesarios: una mesa en una habitación, un pupitre en una sala de clases, un austero comedor de una familia de clase media. En el caso de Neva, la lacónica información entregada al comienzo de la obra es la siguiente: "San Petersburgo en 1905. La sala de ensayos de un teatro. En el centro del escenario hay una pequeña tarima de un metro de alto sobre la que ocurre toda la acción. La única fuente de luz es una estufa eléctrica". ${ }^{2}$ Aquí tampoco el relato se organiza en torno al accionar físico de los protagonistas, quienes más bien se mantienen quietos y hasta inmóviles en largos pasajes, desplazándose apenas en esa "pequeña tarima".

También en Clase las indicaciones son exiguas: "Una sala de clases. Al fondo hay un pizarrón blanco. La Alumna prepara su disertación sobre el escritorio del Profesor". 3

Pero no hay que pensar que este despojo escénico nace de un desinterés por los aspectos "formales" del montaje, sino por un esfuerzo de síntesis. Así lo aclaró el mismo Calderón en su momento:

Hay un texto de Peter Brook donde él describe la relación que tenía con su diseñadora teatral. Desecharon muchas escenografías elaboradas, hasta que ella le propone usar unos palitos de bambú. En cualquier circunstancia uno puede pensar que el diseño se hizo sin diseñador, pero no: detrás de eso había una tremenda intelectualización y revisión para llegar a lo más simple. Lo que quiero decir es que cuando uno se enfrenta al diseñador, tiene una idea, pero a medida que va avanzando el proceso, lo más probable es que se llegue a lo más simple. A mí me gusta que los diseñadores tengan esa visión de humildad, de decir lo que se puede hacer y lo que no. ${ }^{4}$

${ }^{2}$ Guillermo Calderón, Neva, en Teatro I (Santiago: Lom, 2012), 9.

${ }^{3}$ Guillermo Calderón, Clase, en Teatro I (Santiago: Lom, 2012), 115.

${ }^{4}$ Entrevista realizada por Javier Ibacache y Soledad Lagos, en Escuela de espectadores, ciclos 2008-2009 (Santiago: Ediciones Escuela de Espectadores de Teatro, 2010), 51. 


\section{HACIA UN ASCETISMO MATERIAL}

Sumado a esto, hay que agregar que las distintas presentaciones ofrecidas por Calderón apenas han echado mano a la música o a la iluminación como efecto dramático (a lo más, un sorpresivo apagón). Se trata, entonces, de creaciones de claro minimalismo, prácticamente desposeídas de recursos que podríamos considerar "externos", carentes de cualquier espectacularidad. Como metáfora de ello es que los nombres de todas las obras de Guillermo Calderón son sólo una escueta palabra, una especie de disparo donde se juega el todo o nada: Neva, Diciembre, Clase, Villa, Discurso, Beben y Escuela.

La construcción esencial de estas creaciones opera sobre la base de la fuerza del texto, el que somete a los actores a una enorme exigencia expresiva, ya que no posee ningún otro elemento de apoyo más que su entrega física. Liberar la carga dramática intrínseca a sus parlamentos exigirá una comprensión cabal de los temas ahí presentes. Incluso, hay muchos pasajes donde el personaje se mantiene estático, y allí la voz y la economía gestual adquieren una extraordinaria intensidad representativa.

Hace un par de décadas, este ascetismo material hubiera movido a varias personas de teatro a la incredulidad o a la mofa, inmersas como estaban en el derroche pirotécnico. Para sorpresa de muchos, Neva se abre con un extenso monólogo de Olga Knipper, la protagonista, donde cuenta sus anhelos más preciados después de la muerte de su marido, el escritor Antón Chéjov. Y qué decir de una de las obras de Calderón titulada, precisamente, Discurso.

Igualmente, hace algunos años este recurso de sostenerse esencialmente en la palabra hubiera dado la impresión de pobreza y hasta de ignorancia, sobre todo si se piensa que la verbalidad aquí no deriva ni en el absurdo ni en la desintegración. Los parlamentos tampoco se convierten en un balbuceo idiotizado o en un remedo de los lenguajes de la publicidad o de los medios de comunicación, como estuvo tan de moda en los años sesenta.

En sentido contrario a la degradación lingüística, en Calderón la envolvente o incluso apabullante marea verbal alcanza por momentos una cima poética; en otros casos primará la fuerza ideológica de quien expone un argumento, su capacidad de representación de un desgarro íntimo, el soliloquio de alguien extraviado en el dolor y la soledad o, 
también, el relato de una historia que un personaje narra a los demás. Esto último es claramente reconocible en el caso de Diciembre, por ejemplo, cuando Jorge, el soldado chileno que pelea en el norte visita su hogar y refiere las particulares experiencias tenidas por la tropa en el campo de batalla.

Otro ejemplo es cómo le habla el Profesor a la Alumna en uno de los pasajes de Clase, al momento de exponer su turbadora interioridad:

Lo más importante en la vida es encontrar el hambre y saciarla.

Me vas a tener que perdonar, pero hoy no me siento muy humano.

Siento que estoy en un cuerpo de hombre, pero no quepo.

Siento las orejas peludas por dentro.

Pienso en perros atropellados y me da hambre.

Seguramente tú no me conoces de verdad.

Para ti yo debo ser simplemente un hombre generoso, el que te enseña. [Quizá un poco gris, misterioso.

Un hombre duro, ridículamente masculino, atractivo.

Un libro abierto en la parte del clímax [...].

Vivir es como caminar por el bosque.

Ramas van a caer.

Insectos van a morir.

Cuando uno camina por la vida hace daño. ${ }^{5}$

Parecida intimidad se despliega en ciertas escenas de Discurso, donde la protagonista, Michelle Bachelet, dice lo siguiente:

A veces escribo "querido diario" y me quedo mirando el horizonte.

Desde mi casa en el lago.

Es preciosa.

Y está rodeada de árboles.

Yo miro el horizonte.

Miro el agua.

Respiro.

Y siento que todo debería ser así.

$\mathrm{O}$ quedarse así para siempre.

La selva fría del sur.

Y estos árboles coníferos perennifolios.

Para siempre.

Yo me siento tan bien en casa de madera.

${ }^{5}$ Calderón, Clase, 126. 
Con chaleco de lana.

Me siento feliz.

Me siento en la izquierda feliz.

Y yo sé que estoy parada sobre un río de sangre. ${ }^{6}$

Y de esta manera imagina la actriz Olga Knipper el dificultoso estreno que le espera en el teatro de San Petersburgo, exhibiendo una mezcla de ocultos temores y esperanzas:

Ahora tengo pánico. Ya sé lo que va a pasar. Va a llegar la noche del estreno de la obra el próximo sábado y van a venir todas las mujeres sanpetersburguesas a verme. Y las otras actrices a verme. A verme caer, a ver caer a Olga Knipper. A verme desafinar y decir estas hermosas palabras sin alma. Se van a reír en las partes equivocadas y van a estrujar el papel del chocolate. Pero al final, cuando termine la obra y me vean sonreír agradecida y humillada... van a aplaudir felices, con los dientes apretados. Y me van a esperar en el pasillo a la salida del camarín para abrazarme y yo, tímida, ruborizada por el calor, con un halo de perfume cubriendo el olor a sudor del que hiede toda actriz dramática que tenga amor propio... yo voy a agradecer. ${ }^{7}$

Un ejemplo de la función de esta verbalidad desbordante la entregan los múltiples casos en que se impone el tono de gesta, la arenga ideológica, el llamado a modificar radicalmente una situación injusta, aun cuando estos discursos están también teñidos de una fuerte carga afectiva y sentimental, una combinación de elementos ideológicos con otros emocionales. Por ejemplo, hacia el final de Neva, el personaje de Masha exhorta largamente a sus compañeros de trabajo y constituye el centro neurálgico de la representación. Respecto de él, Calderón reflexionó de esta manera: "Lo que yo quise enfatizar en ese monólogo es que la experiencia no fuera estrictamente racional, que uno en un momento dejara de percibir lo que ella dice como discurso lineal y entrara en una actitud o posición emocional". ${ }^{8}$

Así, en una de sus intervenciones, Masha dice lo siguiente:

\footnotetext{
${ }^{6}$ Guillermo Calderón, Discurso, en Teatro II (Santiago: Lom, 2012), 79.

${ }^{7}$ Calderón, Neva, 9.

${ }^{8}$ Isabel Baboun, "Guillermo Calderón: tres motivos para una poética casi trágica”, Apuntes 131 (2009): 26.
} 
Detesto tus gestos ensayados, tus lágrimas negras, tu risa de gorila, tus pausas de merengue. Gallinero, basurero de ideas muertas. Va a haber una revolución y los que quedemos vivos vamos a ser libres. Vamos a tomar, vamos a ganar guerras, vamos a cantar en los funerales. Pero Olga, Aleko, no me hablen de amor, háblenme de hambre. Funden un hospital, márchense, róbense armas, maten a un soldado, maten a un noble, hagan algo que no dé vergüenza ajena, por una vez no hablen con un nudo en la garganta. ${ }^{9}$

En Neva, el lenguaje también sirve para construir recuerdos que se han perdido o realidades imposibles de conocer. Es el ejercicio que reiteradamente ejecutan los actores para recrear un capítulo clave en la vida de Olga: la agonía y muerte de Chéjov. Aquí la palabra sirve, también, para inventar el pasado e incluso para crear una especie de ficción literaria.

\section{LA RESPONSABILIDAD DEL TEATRO EN LA SOCIEDAD}

Con el estreno de Neva (2006), de inmediato llamó la atención que Guillermo Calderón incursionara en temas políticos $\mathrm{y}$, en este caso, uno en particular: la responsabilidad que le compete al teatro al interior de la sociedad donde se desenvuelve. Su trama se centra en el ensayo que tres actores intentan llevar a cabo de El jardín de los cerezos, de Chéjov.

Es el 22 de enero de 1905, llamado por la historia como el Domingo Sangriento. Ese día, unos doscientos mil trabajadores se reunieron a las puertas del Palacio de Invierno, la residencia del Zar Nicolás II. Pedían salarios más justos y mejores condiciones laborales. Se hacían acompañar por íconos religiosos y retratos del zar para demostrar que sus intenciones eran pacíficas. Sin embargo, se ordenó abrir fuego contra la multitud y se estima que murieron unos doscientos obreros y ochocientos quedaron heridos. A partir de ahí hubo una escalada de huelgas y de manifestaciones que, pasados unos años, desembocó en la revolución bolchevique.

Los tres actores de Neva - obviamente su título alude al río de San Petersburgo - están totalmente ajenos a esa terrible realidad que ocurre

\footnotetext{
${ }^{9}$ Calderón, Neva, 51.
} 
en la calle, ocupados en sus recuerdos, en sus sueños individuales y en sus intentos por ensayar la obra. En una primera etapa, los actores se plantean si es posible representar en el escenario el dolor, el amor o cualquier experiencia humana límite sin haberla vivido. Así lo confiesa Aleko: "No puedo actuar, Olga. Me da vergüenza que me miren. ¿Cómo voy a actuar, si nunca he sufrido lo suficiente? A veces me da pena cómo viven los pobres, pero nunca me han roto el corazón. ¿Cómo voy a actuar si nunca he llorado por amor?". ${ }^{10}$

Poco después hay un viraje definitivamente conmovedor, ya que el agitado mundo externo va penetrando en la sala hasta invadir en su totalidad a los protagonistas, al punto de plantearles un dilema esencial: ¿se puede seguir haciendo teatro mientras afuera estalla una crisis social de hondas proporciones que afectará la vida de todos? ¿Pueden estar ocupados hablando de un mundo ficticio, en circunstancias de que el auténtico drama radica en el mundo verdadero? Hay aquí un cuestionamiento al quehacer mismo de una actividad que, al menos en el caso de ellos, sobrevive ensimismada, preocupada de asuntos intrascendentes o domésticos.

Es Masha quien se adjudica las banderas de la gesta revolucionaria que se fragua en la calle, y en la extensa arenga, antes citada, critica la pasividad y enajenación de la gente de su oficio:

La revolución se hizo para gentes como ustedes, para poderlos quemar. ¿Cuánto rato se puede hablar de amor? Me dan ganas de vomitar. Sí, Olga. Se murió tu marido y quieres revivir su muerte porque no puedes actuar. ¿A quién le importa? Afuera hay un domingo sangriento, la gente se está muriendo de hambre en la calle y tú quieres hacer una obra de teatro. La historia pasa como un fantasma, va a haber una revolución. ¿Y quién es tan imbécil para encerrarse en una sala de teatro para sufrir por amor y por la muerte? Me da vergüenza ser actriz. Es tan egoísta, es una trampa burguesa, un basurero, un establo de yeguas. Olga, eres una caballa, no, una burra. Aleko, eres una desgracia. Reza por mí cuando esta ciudad se queme y reza por mí cuando haya revolución para que yo muera en Siberia. Reza cuando te quemen las iglesias. Actores de mierda. Indolentes, ignorantes, pretenciosos, vacíos, cáscaras de maní, tomates podridos. ${ }^{11}$

${ }^{10}$ Calderón, Neva, 50.

${ }^{11}$ Idem. 


\section{LA INVASIÓN DE LOS ESPACIOS INTERIORES}

Tal como ocurre en Neva, otras obras de Calderón exhiben este cerrado mundo interior que, de una $\mathrm{u}$ otra manera, es afectado por lo que ocurre afuera. Paulatinamente, ambos universos - aquel clausurado donde se desenvuelven los personajes, y el exterior, el de la ciudadlogran algún tipo de dramática fusión. En Clase (2008), la Alumna y el Profesor son los únicos miembros de la comunidad escolar que no han asistido a la marcha estudiantil que pide radicales cambios en la educación. Sin embargo, las demandas que se agitan en las calles determinan el accionar de ambos personajes, porque cada uno de ellos resiente interiormente lo que las manifestaciones externas solicitan. En Diciembre (2009), dos mellizas reciben a su hermano, el soldado, para las fiestas de Navidad de 2014, y casi todos los diálogos giran en torno a lo que de manera casi trágica y absurda ocurre afuera: no sólo que hay una encarnizada guerra contra Perú y Bolivia, sino que además se sabe que rebeldes mapuches se han independizado de Chile y amenazan con invadir el país hasta llegar a Santiago, y que el grupo Sendero Luminoso se ha unido a las fuerzas armadas de Perú.

La presencia de aquellos conflictos, que al comienzo parece insignificante, termina por influir en la conducta y en las decisiones de los personajes. Las hermanas Trinidad y Paula disputan agriamente respecto del camino que debe tomar Jorge, el militar: huir hacia el sur y refugiarse hasta que la guerra termine, o volver al frente y enfrentar una muerte segura. La lucha entre los países limítrofes hace brotar violentamente las posturas ideológicas — racista, una; humanista, la otra - de ambas mujeres, así como su discurso - patriotero o pacifista-, dejando en medio a un soldado extraviado en sus preferencias, dudoso y devastado.

Esta conexión entre zonas internas y externas y su mutua determinación es un mecanismo clave en la obra de Calderón para abordar el conflicto político, tan central en su dramaturgia como escaso en la tradición del teatro chileno.

En lugar de esquivar el bulto en relación con este asunto, el autor ha sido enfático en declarar abiertamente sus preferencias y orientaciones artísticas: "El rol de mi teatro es poner en el escenario preguntas que me han acompañado durante todo este tiempo, que tienen que ver 
principalmente con la historia política de mi país. Yo crecí en dictadura, seguí creciendo en democracia y ese trauma de crecer en ese contexto todavía me sigue motivando para seguir escribiendo. El teatro es un excelente lugar para seguir explorando ese tipo de historias, que no son sólo mías, sino que son compartidas por una generación entera". ${ }^{2}$

De forma semejante, en una entrevista, fechada a julio de 2013, declara: "Siempre he sido una persona muy interesada en la política, en la historia. Ocurre que con el tiempo uno va coleccionando opiniones acerca de la vida, acerca del país y esas opiniones se acumulan. Cuando escribo una obra, parto de esas ideas. Otros dramaturgos parten de personajes o de un mundo estético. Yo parto de ideas concretas que tienen que ver con una visión política". ${ }^{13}$

En este contexto, no es extraño que Calderón, como director, haya decidido dirigir Los que van quedando en el camino, de Isidora Aguirre, en 2010: esta dramaturga chilena es una de las pocas voces nacionales que de manera abierta y frontal asumió ciertas realidades políticas, sociales e ideológicas del país.

Estrenada en 1969, Los que van quedando... se relacionaba directamente con la agitada vida ideológica y social de entonces, y su formato respondía al teatro épico-didáctico originado en las teorías de Bertolt Brecht. En su argumento se recreaba el alzamiento campesino en la zona de Ranquil, en 1934, y la posterior masacre ejecutada por la autoridad (los muertos se calculan en más de un centenar). Concebida como una pieza coral —intervienen cuarenta personajes-, al menos tres aspectos se desarrollan en su estructura dramática: el relato de los terribles sucesos ocurridos en el Alto Bío-Bío, las íntimas aspiraciones de los protagonistas por mejorar sus condiciones de vida y las enseñanzas explícitas respecto de la organización popular para acceder al poder y revertir esas injusticias.

El escenario inventado por Calderón para este montaje fue inusual y hasta extravagante: la hermosa sala de la Cámara de Diputados del ex Congreso Nacional, dada de baja en septiembre de 1973. De acuerdo con la obra, en ese exacto lugar los engolados políticos de entonces dis-

${ }^{12}$ Cita contenida en Alejandra Moffat y José Luis Torres Leiva, "Neva, de Guillermo Calderón", video de Escuela de Espectadores, 2011, subido en YouTube el 23 de julio de 2011, https://www.youtube.com/watch?v=FNM_AKZcQno.

13 Daniela González, "Guillermo Calderón, el dramaturgo de la memoria", en revista PAT 56 (2013): 12, www.revistapat.cl/numeros/PAT56/ 
cutieron las noticias referidas a la masacre. Por supuesto, nada hicieron para paliar la tragedia. En este caso, el cerrado recinto que albergaba a los parlamentarios no se conmovió por aquello que exteriormente remecía a la sociedad: una matanza absurda y cruel.

\section{UNA ESTÉTICA POLÍTICA: LOS TEMAS CHILENOS AÚN PENDIENTES}

El llamado teatro "político" que brotó durante la dictadura consistió en plantear sobre el escenario - de manera elusiva, metafórica, poco realista e incluso en clave, nunca de un modo evidente- aquellas realidades impronunciables que escondía el discurso oficial: cesantía, desaparición de personas, restricción al pensamiento disidente, penumbra y opresión de la vida cotidiana. Posteriormente, ya en democracia, en un sector importante del teatro chileno surgió una vigorosa corriente escénica - mayoritariamente juvenil y no necesariamente masiva-, que giró insobornablemente en torno a ciertos temas recurrentes: la asfixiante pobreza material de un importante sector social, la religiosidad alienante, la violencia en las relaciones humanas, los conflictos al interior de la familia, el desconcierto ante un orden social incomprensible $\mathrm{y}$, en fin, la persistencia de marginalidades sexuales que aspiraban a un mínimo reconocimiento del entorno.

La propuesta política de Calderón, en cambio, se planteó de forma más directa, es decir, interpeladora, crítica y cuestionadora del poder, asumiendo una narrativa ideológica que quiere hacerse cargo de temas tan actuales como apremiantes y, de pasada, desmentir que el crecimiento económico de Chile a partir de la década del noventa haya traído bienestar al conjunto de la sociedad. Uno de esos temas, qué duda cabe, es la educación.

En Clase, la perspectiva elegida es mostrar los recónditos fracasos y frustraciones que un sistema deficitario ha infligido a sus protagonistas, ya no sólo estudiantes, sino que también educadores. Y es justamente el Profesor, quien ostenta una visible herida en cabeza, el encargado de exhibir ante su única alumna las otras heridas, las más íntimas, las que hablan de su devastación, tristeza y abatimiento, en un largo y despiadado monólogo que por momentos alcanza un hermoso lirismo. El énfasis no está puesto aquí en el perfil psicológico del perso- 
naje, sino en todo aquello que encarna: él es representante de una legión de maestros que también soñó que un mundo mejor se podía formular desde la sala de clases, y que ahora reconoce su desengaño. Así relata sus orígenes a la Alumna:

Vengo de una familia sencilla.

Guardamos las cosas viejas por si acaso.

Comemos muchísimo pan.

Nunca botamos comida.

Curamos las enfermedades con cariño.

No tenemos ideas, tenemos ganas.

Hemos hecho cosas increíbles por plata.

La belleza nos dura sólo un par de años.

Encontramos todo el vino bueno.

Somos una familia pobre.

De ahí vengo.

Y para allá voy.

A la carbonada.

A la hallulla especial.

A la carne de cañón. ${ }^{14}$

Y en otro pasaje habla de esta manera, al describir su actual realidad:

Mírame.

Yo soy la revolución triunfante.

Porque la revolución es como la belleza.

Va por dentro.

Por eso yo soy como la revolución.

Estoy lleno de errores irreparables y de fracasos vergonzosos.

Yo era mejor cuando me soñaba.

Después de tantos años lo único que queda de mí son las canciones.

Cuando me pongo triste en la calle o en los días helados, cierro los

[ojos y oigo charangos.

Oigo zampoñas.

Oigo quenas.

Cuando me río en las noches heladas mi saliva tiene sabor a vino

[navegado.

Nadie entiende al Che como lo entiendo yo.

${ }^{14}$ Calderón, Clase, 161. 
Porque yo entiendo lo que es querer matar por amor.

Es muy triste ser pobre porque uno se siente bueno.

Uno se siente un Jesús.

Pero la gente no nos reconoce.

Debe ser porque no hacemos milagros. ${ }^{15}$

Y frente a su desencanto por una vida consumida sin éxitos visibles, la Alumna contrapone las esperanzas juveniles de sus compañeros que marchan por las calles:

Quieren ser artistas y vivir del dolor propio. Llorar por no haber tenido todas las oportunidades. Lo que quieren es tener una juventud feliz, una juventud indignada. Tener amigos muertos, cargar armas en vez de fotocopias. Quieren el auto volador. Quieren separarse a susurros y tomar la pastilla del amor. Tienen tantos sueños. Esperan tanto de la música. Quieren parecerse a los animales, principalmente a los cisnes de cuello negro y morirse lento con pasos de ballet. Pero también quieren que se los mire con respeto. Quieren destruir un poco el transporte público. Y tener una relación ambivalente con la policía. Insultarlos pero al mismo tiempo ver en sus manos abiertas la historia triste de los obreros y los campesinos. Quieren sufrir por no poder comer como reyes. Mis compañeros quieren educación, pero necesitan aprender a sentarse. ${ }^{16}$

\section{¿QUÉ HACER CON UN PASADO DOLOROSO?}

En el caso de Villa (2011) se muestra otro tema político y social tan pendiente como lacerante: la herencia relativa al atropello de los derechos humanos sufridos en dictadura. Se trata de la discusión en tiempo real de tres jóvenes mujeres de izquierda, a quienes una comisión especializada les ha encargado que decidan el destino de Villa Grimaldi, que durante los primeros años del régimen militar sirvió a los servicios de seguridad como lugar de detención y tortura (cuartel Terranova). Como se sabe, después de unos años la villa fue destruida para que no quedaran rastros físicos de los terribles acontecimientos que allí habían ocurrido.

\footnotetext{
${ }^{15}$ Calderón, Clase, 160.

${ }^{16}$ Calderón, Clase, 163.
} 
Para estas protagonistas — sólo al final saben que fueron escogidas por ser hijas de mujeres que pasaron por la villa-, son dos las posibilidades: restaurarla puntillosamente tal y como era, y así ofrecer a los visitantes el espacio que cobijó aquellos horrores, o levantar un museo de arte vanguardista que por una vía más indirecta y artística guarde la memoria nacional. Aunque la áspera polémica del trío sirve para evocar las reales circunstancias vividas por la sociedad chilena del período, otro es el tema central que se perfila: la complejidad, y hasta incomodidad, que significa para el Chile actual la existencia de aquellos sucesos y de qué manera se pueden enfrentar.

En relación con ello, Francisca se opone a la idea de un museo porque suena parecido a colocar "punto final". Dice: "Como que el tema ya pasó, como que se están sanando las heridas, como que estamos tan unidos como país que ya podemos gastar la plata en un museo de la memoria que parece museo de arte contemporáneo". ${ }^{17}$

Así, Villa Grimaldi se convierte aquí en la metáfora de una herencia indeseada (torturas, vejaciones, violaciones); un legado engorroso y triste que nadie ha sido capaz de asumir en plenitud; un tema todavía pendiente, aunque su presencia es inevitable y su olvido, inconcebible. Las indecisiones, dudas, planteamientos y replanteamientos de las tres protagonistas muestran precisamente ese no saber qué hacer con aquel pasado. La única solución, imposible, por cierto, es que no hubiera existido, tal como lo propone Macarena casi al final de la obra:

Pasó. Pasó. Pasó. Y ya no hay nada que hacer. Porque ya pasó. Y si me confundo con lo que ustedes dicen, es que me da lo mismo. Me da lo mismo. No me importa lo que hagan con la villa. Lo que a mí me gustaría es que nunca hubiera habido villa. Nunca. Y yo lo que realmente haría sería reconstruir la villa como era antes de que fuera villa. Reconstruiría la antigua casa solariega. Para mirarla y tener la ilusión de que aquí nunca pasó nada. Y sería una casa feliz. Y la llenaría de niñas. Sería la máquina del tiempo. Aquí no ha pasado nada. Como si estuviéramos todas vivas. Y tendría olor a carbonada. $\mathrm{Y}$ tendría gallinas. $\mathrm{Y}$ vacas [...]. En la puerta que da a la calle pondría una placa de bronce que diga VILLA. Villa. Sí. VILLA va a decir. Lo que pasó aquí, no debería haber pasado nunca. Pero pasó. ${ }^{18}$

${ }^{17}$ Guillermo Calderón, Villa, en Teatro II (Santiago: Lom, 2012), 41.

${ }^{18}$ Calderón, Villa, 64. 
Discurso también fue estrenada en 2011. Se trata del hipotético discurso de despedida de la Presidenta Bachelet en las últimas horas de su primer mandato. El personaje es encarnado por tres actrices, quienes se alternan los parlamentos. Cada una tiene terciada en el pecho una banda de un solo color: blanca, azul y roja, respectivamente.

Aquí, la mandataria saliente se aleja del protocolo formal que imponen las circunstancias y habla de sus íntimos sentimientos y contradicciones vitales: a pesar de su antigua militancia socialista, de ser hija de un general de la Fuerza Aérea torturado por sus subalternos hasta morir, de haber estado ella y su madre detenidas después del Golpe de Estado de 1973, era imposible que como Presidenta asumiera una actitud revanchista frente a lo ocurrido. Tampoco era imaginable que intentara imponer un modelo socialista ortodoxo, una especie de neo Unidad Popular. Así lo rememoran sus palabras:

Pero si se acuerdan bien tampoco me eligieron para cambiarlo todo. Me eligieron para otra cosa.

Para darse un gusto.

Para ser felices por un rato.

Para que les amasara un pan con sabor a justicia.

Para ver mi foto sonriendo en oficinas públicas.

Para que fuera la mejor Presidenta de la historia. ${ }^{19}$

En su monólogo, este único personaje desarrolla reflexiones, historias, impresiones personales y duras confesiones. En relación con su percepción de la pobreza y al dolor que todo aquello le causa, sus palabras están henchidas de emoción y sinceridad. Sin embargo, debajo de su humanista compasión va trazando la dificultad central de su gobierno: la imposibilidad de solucionar a fondo los problemas sociales de la nación, ceñida por la camisa de fuerza de un sistema económico heredado que no estaba en el origen de su impronta:

Porque este modelo económico sí ha creado trabajo.

Pero muy mal pagado.

Muchos trabajan y siguen siendo pobres.

Y parece que a mucha gente eso igual le gusta.

${ }^{19}$ Calderón, Discurso, 76. 
Mal que mal me eligieron para administrar ese modelo.

Ese modelo.

La economía social de mercado.

El modelo neoliberal de la derecha.

El mismo modelo que ahora no le da trabajo a más del diez por ciento.

Tienen que entenderme.

Yo he sido médica por años.

He tratado de ayudar a niños que son nietos de la guerra.

Pero la economía no la entiendo profundamente.

Y nadie la entiende realmente.

Los economistas son gente simpática, pero les pasa lo que nos pasa a

[todos.

Se nos muere el paciente.

Se nos cae la casa.

Nos queda chueca la basta del pantalón del matrimonio. ${ }^{20}$

Discurso es un perfil no sólo humano - atravesado por un fino humor-, sino también una radiografía de las modificaciones sufridas por aquellos remotos soñadores que anhelaban transformar radicalmente la sociedad, y que ahora se focalizan en temas más domésticos y acotados, en una especie de resignación respecto del devenir de la historia. Es decir, para la dramaturgia de Calderón, la caída de las utopías es otro tema político pendiente de la sociedad chilena. EP

${ }^{20}$ Calderón, Discurso, 86. 